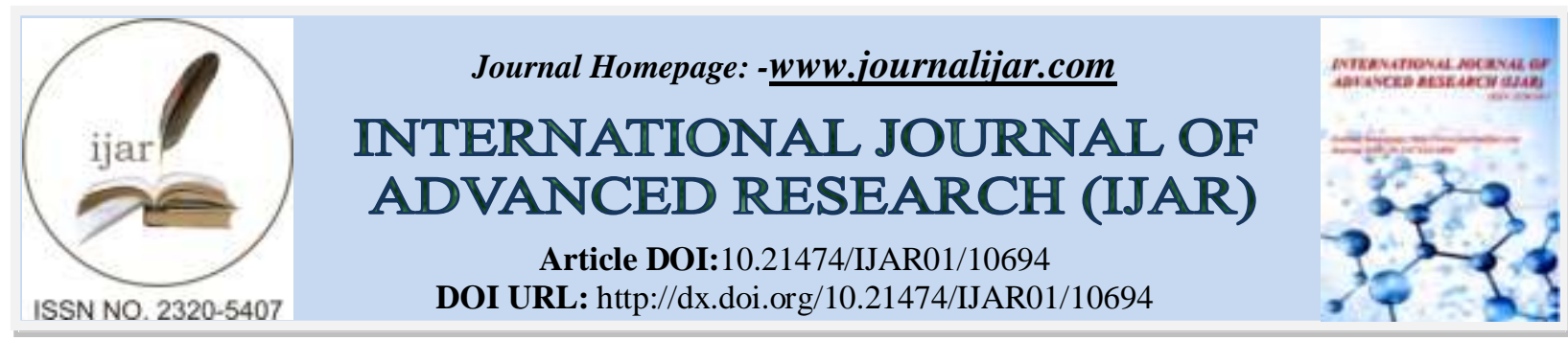

RESEARCH ARTICLE

\title{
REVIEW: THE STUDY OF EFFECTOFBOTANICALS AND NUTRACEUTICALS IN FEMALE SEXUAL DYSFUNCTIONAND IN MENOPAUSE
}

Ganesh Kamath, Supriya Yadav, Bharat Acharaya and Rashmi Mungekar

Vital Neutraceuticals Pvt.Ltd., Mahararshtra, India.

\section{Manuscript Info .............. \\ Manuscript History \\ Received: 20 January 2020 \\ Final Accepted: 22 February 2020 \\ Published: March 2020 \\ Key words:- \\ Menopause, Soy Isoflavones, Tribulus terrestries, Mucunapruriens, Aphrodisiac}

\begin{abstract}
Substances which are used to treat sexual dysfunction or to improve sexual behaviour and satisfaction in humans and animals are called "aphrodisiac". Uses of plant material to treat sexual disorder and in menopausal women is a long back history in the different system of medicine and it was practiced by different type of Vaidya's and traditional healer in almost all the countries in the world, like China, India, Egypt, Rome and Greek. Even though there was an unavailability of the scientific data, these substances have been used as aphrodisiac. During the historic times Soy Isoflavones, Tribulusterrestries, Mucunapruriens, L- Arginine, Grape Seed Extractand other plants have been investigated for its aphrodisiac activity and for its role in menopause by in vivo and in vitro model. Even though the study showed positive response to a particular substance, there is always a need to run the clinical trial before administering the tested drug in human being. The present review article summarizes the plant material which has been tested for its aphrodisiac activity and its effect in menopause in different experimental model (in vitro, in vivo on animal models, or in human clinical trials) and comply its claim in the different system of medicine.
\end{abstract}

Copy Right, IJAR, 2020,. All rights reserved.

\section{Introduction:-}

Sexual function is an important aspect of life for many women, regardless of age. Sexual function is closely correlated with overall well-being and relationship satisfaction. ${ }^{1-3}$ Most women continue to consider sexual function important as they age. ${ }^{4-6}$ However, $45 \%$ of midlife women have sexual problems, ${ }^{2,7}$ and $15 \%$ have a sexual problem that causes significant personal distress. ${ }^{7}$ Female sexual dysfunction remains underrecognized and undertreated by health care providers. In this article, the authors review the factors responsible for female sexual dysfunction, examine how sexual function changes during the midlife transition, and discuss new and emerging treatments.

Despite rapid current and anticipated growth in the number of women who will spend a substantialportion of their life span in the postmenopausal period, the nature, incidence, and prevalence of changes in sexualfunction during and after the menopausal transition remain poorly characterized.

Corresponding Author:-Supriya Yadav

Address:-Vital Neutraceuticals Pvt. Ltd., Mahararshtra, India. 


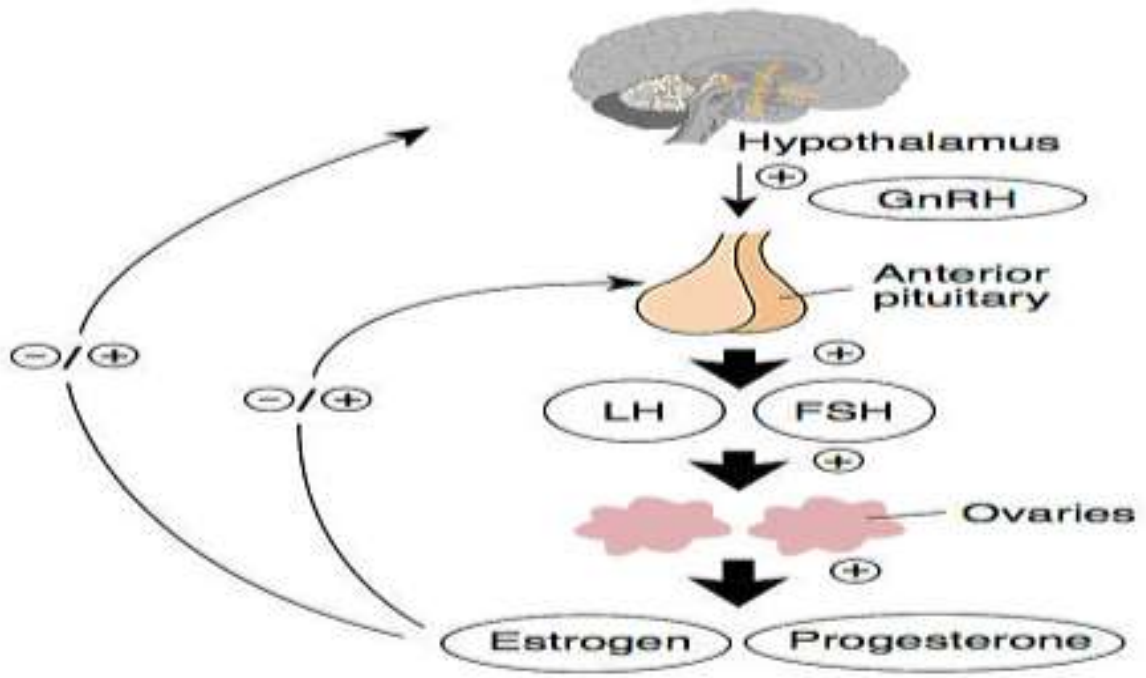

Fig 1:- Hypothalamus - Pituitary - Gonad (female) Endocrine Axis ${ }^{41}$.

The hypothalamic-pituitary-gonadal axis (HPG axis) refers to the hypothalamus, pituitary gland, and gonadal glands as if these individual endocrine glands were a single entity. Because these glands often act in concert, physiologists and endocrinologists find it convenient and descriptive to speak of them as a single system. ${ }^{41}$ The HPG axis plays a critical part in the development and regulation of a number of the body's systems, such as the reproductive and immune systems. Fluctuations in this axis cause changes in the hormones produced by each gland and have various local and systemic effects on the body.The axis controls development, reproduction, and aging in animals. Gonadotropin-releasing hormone $(\mathrm{GnRH})$ is secreted from the hypothalamus by GnRH-expressing neurons. The anterior portion of the pituitary gland produces luteinizing hormone (LH) and follicle-stimulating hormone (FSH), and the gonads produce estrogen and testosterone. ${ }^{41}$

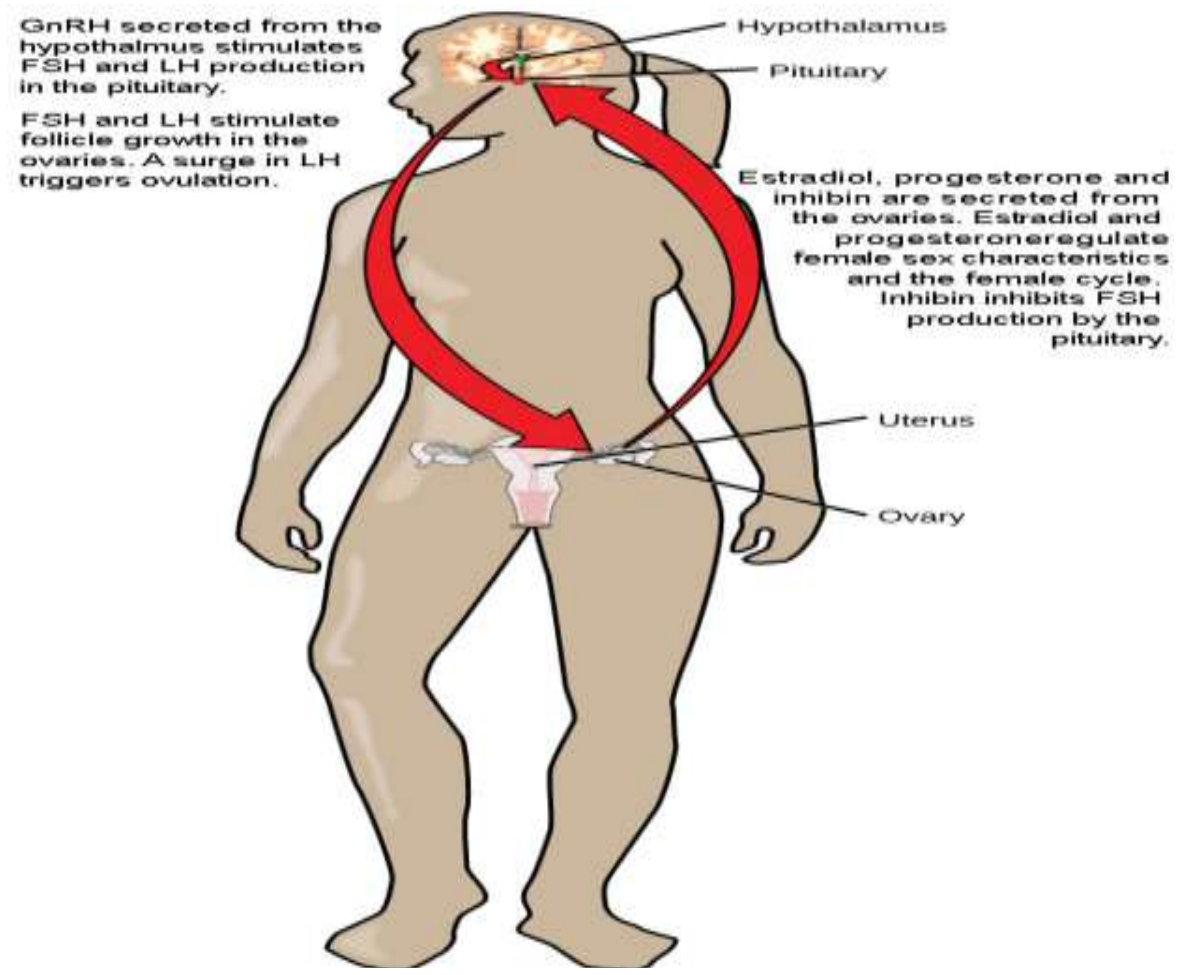

Fig 2:- Hormonal regulation of the female reproductive system involves hormones from the hypothalamus, pituitary, and ovaries. ${ }^{40}$ 
In females, FSH stimulates development of egg cells, called ova, which develop in structures called follicles. Follicle cells produce the hormone inhibin, which inhibits FSH production. LH also plays a role in the development of ova, induction of ovulation, and stimulation of estradiol and progesterone production by the ovaries, as illustrated in Figure 2. ${ }^{40}$

Estradiol and progesterone are steroid hormones that prepare the body for pregnancy. Estradiol produces secondary sex characteristics in females, while both estradiol and progesterone regulate the menstrual cycle.In addition to producing FSH and LH, the anterior portion of the pituitary gland also produces the hormone prolactin (PRL) in females. Prolactin stimulates the production of milk by the mammary glands following childbirth. Prolactin levels are regulated by the hypothalamic hormones prolactin-releasing hormone (PRH) and prolactin-inhibiting hormone (PIH), which is now known to be dopamine. PRH stimulates the release of prolactin and PIH inhibits it.The posterior pituitary releases the hormone oxytocin, which stimulates uterine contractions during childbirth. The uterine smooth muscles are not very sensitive to oxytocin until late in pregnancy when the number of oxytocin receptors in the uterus peaks. Stretching of tissues in the uterus and cervix stimulates oxytocin release during childbirth. Contractions increase in intensity as blood levels of oxytocin rise via a positive feedback mechanism until the birth is complete.Oxytocin also stimulates the contraction of myoepithelial cells around the milk-producing mammary glands. As these cells contract, milk is forced from the secretory alveoli into milk ducts and is ejected from the breasts in milk ejection ("let-down") reflex. Oxytocin release is stimulated by the suckling of an infant, which triggers the synthesis of oxytocin in the hypothalamus and its release into circulation at the posterior pituitary. $^{40}$

\section{Changes in Sexual Function During Midlife:}

Sexual function declines during midlife. The Study of Women's Health Across the Nation and others found that this decline corresponds with the menopausal transition, including in women who have hysterectomies.Although symptoms such as vaginal dryness increase over the same period, changes in sexual function are independent of other symptoms associated with the menopausal transition. Declines in sexual activity during midlife are multifactorial. One prominent reason that women do not engage in sexual activity is lack of a partner. Women who are sexually active before menopause appear to continue to engage in sexual activities during midlife, despite poor "functional sex."Lifestyle factors, including sufficient sleep and physical activity, contribute to more positive sexual functioning during midlife. ${ }^{8}$

The sexual response is generally divided into four phases: desire, arousal, orgasm, andresolution. Unfortunately, this model does not hold consistently true for all women because of themultifactorial hormonal, neuronal, and psychosocial interactions that motivate female sexualresponse. The biology of desire is poorly understood in women, but it is hypothesized that HSDD (hypoactive sexual desire disorder)is caused by some mal-adaptive neuronal process that precludes psychological priming for sex. ${ }^{9}$

\section{Factors that Affect Female Sexual Function:}

\section{Biologic Factors:}

Hormones, Menopausal Symptoms, Menopause is characterized by ovarian follicular exhaustion and hypogonadism.Reduced ovarian steroidogenesis leads to the development of genitourinary syndromeof menopause (GSM), ${ }^{10}$ which adversely affects the genital system and lowerurinary tract in menopausal women and significantly contributes to sexual dysfunction. ${ }^{11}$ More than half of menopausal women experience GSM, which is responsiveto local estradiol. Unlike vasomotor symptoms, which often decrease over time,GSM does not resolve and recurs after discontinuation of estrogen. ${ }^{12,13}$

Table 1:- Medical and psychiatric conditions that are associated with female sexual dysfunction.

Cardiovascular disease

Diabetes mellitus

Neurologic disease (stroke, multiple sclerosis, spinal cord injury)

Hypertension

Substance use disorders

Genitourinary syndrome of menopause

Breast, ovarian, uterine, and cervical cancer

History of gynaecologic surgery

Chronic renal failure 
Urinary incontinence

Psychosocial Factors:

Several of the following psychosocial factors that are common during midlife are associated with sexual dysfunction:

1. Mood symptoms, such as depression and anxiety

2. Life stressors, such as career and family demands

3. A history of trauma, particularly sexual trauma

The development of depression and anxiety symptoms during the menopausal transition is common.Mood disorders and sexual dysfunction are highly comorbid,with $25 \%$ to $75 \%$ of depressed women reporting sexual problemseven when controlling for other factors. ${ }^{14-16}$ It is important for providers to screen women with sexual complaints for depression and anxiety symptoms and recognize that not all women with sexual dysfunction have a mood disorder. Everyday life stressors also have a negative impact. ${ }^{16-18}$ Midlife women may be caring for children of their own, may have adult children return home, and/or be caring for aging parents. ${ }^{18} \mathrm{Job}$-related stress and financial concerns are also common. ${ }^{18}$ Providers should be attuned to the effects of life stressors and work with women to develop stress reduction strategies, such as mindfulness meditation.

\section{Interpersonal Factors:}

Most midlife women are sexually active with a partner,and partner-associated issues can affect the woman's sexual function, as follows:

1. Positive relationship aspects: higher relationship satisfaction and intimacy are associated with better sexual function, ${ }^{19,20}$ and the ability to openly communicate with one's partner is of key importance. ${ }^{18}$

2. Loss or gain of a partner: Many women experience the loss of a partner (to death, divorce, or separation) at midlife, and some gain a new partner, both of which can affect sexual function.Gain of a new partner is associated with increased desire, arousal, and emotional satisfaction with sex. ${ }^{15}$

3. Issues affecting aging partners: Partners may develop medical problems, medications, or sexual dysfunction that can affect the woman's sexual function. In particular, erectile dysfunction in male partners is associated with decreased sexual function and satisfaction in female partners. ${ }^{18}$

\section{Part I:}

Medicinal Plants as Alternative Treatments for Female Sexual Dysfunction:

Female sexual dysfunctions (FSD) are understood as multifactorial and multidimensionalhealth issues that are associated with physical andemotional conditions. ${ }^{21}$ In this regard, the use of medicinal plants for several diseases has increased in Western cultures ${ }^{22}$ and in other parts of the world. A Japanese study suggested that complementary and alternative medicines are used more frequently by females than males ${ }^{23}$. Most women report thepreference for herbal products based on the idea that these products are natural, safe, and more congruent with their values and lifestyles.

This review focuses on the use of medicinal plants for the treatment of FSD to provide additional evidence of possible therapeutic approaches for women with sexual problems. The medicinal plants described below have clinical and popular use and have been widely used around the world in many different cultures and in several medical approaches. More specifically, we have highlighted the medicinal plants that are commonly used for FSD, mainly in climacteric women. Theplants presented in this review, such as Tribulus terrestries, Mucunapruriens, LArginine, Grape Seed Extract, have effects on the female reproductivesystem, and their use in FSD studies has been proposed due to their mechanisms of action.

\section{Tribulus terrestries:}

Prescribing Tribulus extract for women can increase desire score in women who suffer from loss of sex desire. However, according to our knowledge there has not been any similar research on the impact of Tribulus extract in improving women's sex desire in childbearing age. The effect of testosterone in improving desire in menopausal women has been confirmed by studies that have looked at women's sex drive and how to boost it. The role of conjugated testosterone in treating lack of sex drive has been emphasized. Currently testosterone is the only approved drug for treatment of HSDD inmenopausal women, particularly for those have surgicallyinduced menopause. However, Tribulus is the only drug which not only improves the sexual desirein women but also it does not have any unexpected side effects in patients. ${ }^{24}$ 
Tribulus terrestris have a potential double effect, improving sexual desire through an increase in free testosterone and also improving arousal by means of a vaginal vasodilating effect. ${ }^{25} \mathrm{~T}$. terrestrisis often used in the treatment of infertility, decreased libido, and erectile dysfunction. It is also used among athletes to increase muscle resistance and improve performance in sports, although scientific evidence to support this effect is lacking. ${ }^{21}$ The active components of $\mathrm{T}$. terrestrisinclude the steroidal glycoside saponins furostanol and spirostanol, which are found in the leaves of the plant. $^{26}$

Protodioscin is a chemical substance derived from the T. terrestrisplant that has been confirmed to increase sexual desire and improve erections by means of conversion of protodioscin to (Dehydroepiandrosterone)DHEA. ${ }^{21,27}$ In animal studies, increased testosterone levels along with increased dehydrotestosterone and DHEA are suggestive of aphrodisiac activity. ${ }^{21,26,28-30}$

The co-occurrence of enhanced female sexual function and increased DHEA levels is suggestive of physiological alterations underlying clinical improvement following treatment. The study of Nunes et al strongly support the safety and effectiveness of T. terrestrisextract in the treatment of female sexual dysfunction ${ }^{31}$

Tribulus terrestris, puncture vine has long been used in traditional medicine to treat impotency and improve sexual functions. The study of Esfandiariet al,investigated the effect of Tribulus trestris extract on ovarian activity of immature wistar rat. Results showed that number of corpus luteum and diameter of theca interna increased in treatment group as compared with control group. Number of secondary and graafian follicles after 14 days treatment was higher than control and 7 days treatment. The results indicated that Tribulus terrestris induces corpus luteum formation and growth and therefore beginning of puberty with its LH-like activity. In addition, increased in corpus luteum diameter may relate to increased progesterone production. ${ }^{32}$

Opioids can exert adverse effects on the body. Morphine, an opioid drug,reduces hormone levels and fertility, and causes sexual activity disorders. Tribulus terrestris(TT) is a traditional herbal medicine used to enhance sexual activities. The studyinvestigated the possible role of TT on sex hormones and gonadotropins with the intent toshow its usefulness in treating fertility disorders in opioid users. Overall, except forfollicle-stimulating hormone (FSH), morphine reduced most of the gonadotropins andsexual hormones. Whereas TT caused a considerable increase $(\mathrm{p}<0.05)$ in the hormonesin the treated addicted group, there was only a slight increase in the treated control group.Oral consumption of TT could markedly antagonize the reduction of sexhormones and gonadotropins (except for FSH) due to morphine addiction. ${ }^{33}$

Aphrodisiacs are substances, foods, drinks, and behaviours that throughout history have had reputations for making sex more attainable and pleasurable. It has been long believed that TT possesses aphrodisiac properties purportedly attributed to its ability to influence the levels or mimic function of sex hormones. This optimistic and hopeful notion was initially developed on epistemological assumptions and further nurtured andfostered by the persuasive but, perhaps, disquieting attraction to the idea of "natural" versus "artificial". The popularity of medicinal products from TT is expanding at aremarkable pace among consumers who are attempting to enhance their sexual health. ${ }^{34}$

Using three double-blind randomized controlled trials, this selective systematic analysis reviewed the safety and efficacy of Tribulus terrestris in improving the sexual desire in women with HSDD older than 18 years of age. Exclusion criteria were exhaustive and included both medical and psychological conditions, medications, and other sexual dysfunctions in addition to HSDD. All three trials using the FSFI and QS-F questionnaires showed that in these women with HSDD, taking Tribulus terrestris was associated with a statistically significant increase in sexual desire. ${ }^{9}$

Tribulus terrestris safely and effectively improve sexual desire in women with HSDD. No serious orlife-threatening adverse reactions were reported.

\section{Mucunapruriens:}

All parts of M. prurienspossess valuable medicinal properties in traditional system of medicine in India and West Africa used as a uterine stimulant and aphrodisiac. The seeds have been reported to be antidiabetic, antifungal, antioxidant activity, hypotensive, hypocholesterolemic, aphrodisiac, immunomodulator, cough, debility (physical weakness due to illness), dysentery, dysmenorrhea, fertility, impotency, night dreams, sterility, tuberculosis, uterine stimulant. The seeds are astringent, laxative, anthelmintic, aphrodisiac and tonic. ${ }^{35}$ 
The seeds of M. prurienshave nonprotein amino acid (3-(3, 4-dihydroxyphenyl)-1-alanine) L-dopa for the first time in 1937 as a major constituent and mainly in seeds. L-DOPA is present at about $1 \%$ by fresh weight in leaves and roots of M. pruriens. The fully matured M. pruriensseeds ranges 3.6 to $4.2 \%$, pod-pericarp 0.14 to $0.22 \%$, leaves 0.17 to $0.35 \%$, stems 0.19 to $0.31 \%$ and roots 0.12 to $0-.16 \%$ and the highest amount of L-DOPA was found in half mature seeds. The unusual non protein amino acid and a direct precursor to the neurotransmitter dopamine, is an important brain chemical involved in mood, sexuality and movement. ${ }^{36}$

The increase in the number of oocytes released at ovulation with the use of M. pruriens has also been reported in previous report by using the seed. It can be attributed to the presence of L-Dopa in the leave. Increase in dopamine, a metabolite of L-Dopa has been reported to stimulate gonadotrophin releasing hormone (GnRH), which in turn activates the secretion of follicle stimulating hormone (FSH), resulting in the increase in oocyte number. This increase in oocyte number is thus evident as the corresponding increase in the reproductive outcome. ${ }^{37}$ Sexual behaviour tests showed that the ethanolic seed extract of M. pruriens possesses significant sexual function enhancing activity. ${ }^{38}$

Significant uterine weight gain was observed in moist and dry condition which might be due to the presence of estrogenic activity in the plant M. pruriens which was administered in the ethanolic extract form to the mice. Thus, M. pruriens possess a good estrogenic activity. ${ }^{39}$

It can therefore be said that the use of M. pruriensincreases fertility and can be used as a potent medication in female sexual dysfunction.

\section{Grape Seed Extract:}

Oxidative stress is an important inducement in ovarian aging which results in fecundity decline in human and diverse animals. As a potent antioxidant, grape seed proanthocyanidin extract (GSPE) was investigated to ameliorate chicken ovarian aging. Firstly, ovarian antioxidant capacity of hens at different ages (90, 150, 280, and 580 days old) was compared to elucidate its age-related changes. Subsequently, a D-gal-induced $(2.5 \mathrm{mg} / \mathrm{mL}) \mathrm{aging}$ ovarian model was established and the cultured ovarian tissues were treated with GSPE at $5 \mu \mathrm{g} / \mathrm{mL}$ for $72 \mathrm{~h}$ to evaluate the putative attenuating effects of GSPE on ovarian aging. Meanwhile, ovaries of D280 (young) and D580 (old) were treated with GSPE for $72 \mathrm{~h}$ in culture to verify the protective effects of GSPE on natural aging ovary. The results showed that GSPE could rescue the antioxidant capacity decline by increasing the antioxidase activities and their gene expression in either D-gal-induced or natural aging ovaries. ${ }^{42}$

Moreover, GSPE could maintain the homeostasis between cell proliferation and apoptosis in the D-gal-induced and natural aging ovaries, as well as alleviate D-gal-induced nucleus chromatin condensation in the ovarian granulosa cells. In conclusion, GSPE treatment can effectively prevent the ovarian aging process in hens by reducing oxidative stress $^{42}$ which will help to maintain the sexual health of females at later age of their life.

Supplementation of polyphenols can serve as an alternative method to stimulate estrogen secretion. Grape seeds contain various polyphenols at a concentration of approximately $2178.8 \mathrm{mg} / \mathrm{g}$ gallic acid equivalent (GAE), which is considerably higher than that observed in grape skin (374.6 mg/g GAE) and grape leaves (351.6 mg/g GAE). Grape seed extract (GSE) supplementation is known to induce estrogen synthesis by normalizing estrogen receptor deficiency. ${ }^{43}$ Grape seed polyphenols also have several beneficial health effects, most notably, anticancerand vasorelaxant effects. ${ }^{44}$

One of the most abundant ingredients of grapes are phenolic compounds which are present in large amounts. Grape seed is one of the richest sources of polyphenols, which exhibit antioxidant, free radical scavenging properties, and lipid lowering effects. The most common polyphenols of grape seeds are procyanidins ranging in size from monomers to long-chain polymers, such as catechin, epicatechin, and procyanidin B2. Because of its different properties, grape seed extract (GSE) has been proposed to be a good nominee for decreasing metabolic and cardiovascular changes related to obesity and metabolic disorders. ${ }^{45}$

Ingle et al evaluated E1, E2, estrogen conjugates, androstenedione and testosterone levels in 191 women who were treated with anastrozole $1 \mathrm{mg} /$ day as adjuvant therapy for resected early $\mathrm{BC}$. Their results showed large interindividual variation in anastrozole metabolism and its effect on circulating estrogens in postmenopausal patients. The authors suggested that this commonly used agent for the treatment of $\mathrm{BC}$ should be evaluated in 
pharmacogenomics studies aimed at identifying genetic variation in drug metabolism. A similar mechanism could be responsible using GSE as an $\mathrm{AI}^{46}$

Proflavanol is a plant derived antioxidant combined with extracts from grape seeds. It actually helps your body remove waste (free radicals) produced by cells when they use oxygen.Also, it increases blood circulation to the pelvic area, decreases inflammation, and reduces the impact of stress on the body. The overall effect of these changes is an enhanced uterine environment that is better prepared for implantation and a healthy pregnancy.

Growing evidences demonstrated that the supplementation of GSPE as an antioxidant is an efficient measure to reduce the oxidative stress in the ovary. The protective effects of GSPE against oxidative stress on natural aging ovarian tissues. Thus, GSPE has an effect on the sexual health of woman and can be used as a potential herbal medicine.

\section{L-Arginine:}

Nitric oxide (NO) has been well established as the key mediator for the up-regulation of cyclic guanosine monophosphate (cGMP) which in turn mediates circulation and sexual function. L-arginine is a precursor of NO. The conversion of L-arginine to NO is mediated by nitric oxidesynthase (NOS). Increasing tissue L-arginine levels result in the increase of NO and cGMP. Supplementation with L-arginine has been shown to play a role in restoring endothelial-derived NO production in many disorders which reduce or impair this production, including diabetes, hypercholesterolemia, and mechanisms related to hypertension. Studies also point to the role of L-arginine in reducing cell-mediated breakdown of $\mathrm{NO}^{47}$

Nitric oxide synthase (NOS) is present in the deep arteries, veins, and capillaries of the human vagina. NOS fibres related to vascular smooth muscles are also found in the vagina of the cow, pig, and mouse. Such location suggests that nitric oxide plays a role in the control of vaginal blood flow and/or vaginal contractile activity. In this view, the downregulation of NOS in the rat vagina upon estrogen withdrawal may be significant to the pathophysiology of female sexual dysfunction. ${ }^{48}$ The proposed mechanism of enhancement of the nitric oxide (NO) pathway with Larginine only explains these results. NO derived from L-arginine is central to smooth muscle relaxation, vascular dilatation, and the regulations of circulation. ${ }^{49}$

VasoactiveIntestinal Polypeptide(VIP) areabundant in the vagina, where they innervate bloodvessels and smooth muscle in the vaginal wall, andform a plexus beneath the epithelial layer. The highest levels of VIP in the femalereproductive tract are found in the vagina and cervixwith lower levels in uterine and fallopian regions. Physiologically, VIP has been implicated in thevaginal vasodilatation and transudation, or vaginallubrication, that occur during sexual arousal. Neuropeptide Y (NPY) is alsoabundant in neurons in the human female genitaltract, and is contained in nerves innervating bloodvessels, as well as in nerves that form a subepithelialplexus. ${ }^{50}$

NPY and VIP are well established as vasomotorneurotransmitters, being involved in neural control ofblood flow. In the human and guinea pig uterineartery NPY causes vasoconstriction while VIP causes vasodilatation ofvaginal blood vessels. NO was first established as asubstance released from endothelial cells to causevasodilatation, but it too canbe released from nerves innervating the uterine artery,thereby mediating vasorelaxation. The distribution of neuronal NOSwithin nerves innervating the human vagina has notbeen previously demonstrated, but in the wall of themouse vagina NOScontaining nerves form a densenetwork, and intrinsic ganglion cells may also befound, as well as a dense subepithelial plexus, andperivascular localisation. ${ }^{50}$

From studies on laboratory animals it has beensuggested that nitric oxide (NO) may also function asa neurotransmitter in male and female genital organs,including the uterus and vagina.NO is likely to have asensory role, since NOS has been found in asubpopulation of sensory neurons in the DRG(dorsal root ganglia) ofhumans, monkeys and rats. ${ }^{50}$

The NO-cGMP pathway plays a key role in the male and female genital sexual arousal response.Nitric oxide synthase (NOS) utilizes L-arginine and oxygen as substrates to produce nitric oxide (NO). Arginase is a metalloenzyme that catalyzes the hydrolysis of L-arginine to produce L-ornithine and urea. It isproposed that arginase competes for L-arginine and reduces NOS activity in genital tissues, thus modulating sexual function. Using 2 transition state analogue inhibitors of arginase, 2(S)-Amino-6-boronohexanoic acid (ABH) and S-(2boronoethyl)-L-cysteine (BEC) have been characterized arginase activity in penile and vaginal tissue. Neither of 
these inhibitors has activity against NOS. Thus, ABH and BEC are useful compounds for examining the role of arginase in genital tissue physiology, without directly influencing NOS activity. We present data to suggest that arginase may regulate NO production by competing for endogenous pools of L-arginine. In this fashion, arginase is an indirect regulator of penile and vaginal blood flow and specific arginase inhibitors may improve genital blood flow during sexual arousal. As evidenced by the upregulation of arginase in specific disease states, its distribution in the vagina, and its modulation by sex steroid hormones, this enzyme may also participate in numerous other physiological and pathophysiological processes, such as tissue growth, fibrosis, and immune function. ${ }^{51}$

Thus, the potential role of nitric oxide in mediating vaginal sexual response should not be underestimated.

\section{Part II:}

Effect of Soy Isoflavones, Tribulus terrestries, Mucunapruriens, L- Arginine, Grape Seed Extract, on Menopausal Women:

In developed countries, communities and midwives are showing a renewed interest in the use of herbal and alternative medicine. Western oriented medicine and health systems, introduced during the colonial era, did not eliminate well-established systems of traditional medicine and many Africans learnt to use both health systems depending on the availability or the nature of the illness. Drugs obtained from natural sources are perceived to have the least risk and low side effect profiles, while having the ability to cure medical disorders in much the same way as their synthetic counterparts. ${ }^{59,60}$

Phytoestrogens are a group of biologically active compounds that can play an important role in maintaining hormone balance and overall health. Their health benefits are attributed to mechanisms that influence estrogen receptor sites, sex hormone binding globulin, cell proliferation, angiogenesis, cholesterol synthesis, and platelet aggregation, in addition to antioxidant and anti-inflammatory properties. Because of their estrogenic activity, phytoestrogens are particularly important for women hence, they provide many of the health benefits of hormone replacement therapy, such as protecting against cardiovascular disease and osteoporosis, while simultaneously protecting breast tissue. ${ }^{61,62}$

\section{Soy Isoflavones:}

Soy isoflavones are nonsteroidal molecules structurally and functionally related to 17ß-estradiol. Three major isoflavones found in soybeans are genistein, daidzein, and glycitein. When they bind to estrogen receptors $\alpha$ and $\beta$ via their phenolic rings, they may exert agonistic, antagonistic, or partially agonistic/antagonistic effects at the receptor. Isoflavones occur in soybeans as glucosides. When they are consumed, they undergo metabolic changes in the gastrointestinal system. A sugar moiety is removed, and metabolically active aglycons form. One third of aglycon is absorbed as free isoflavone, and two thirds are converted to metabolites such as equol and p-ethylphenol by the intestinal microflora, which are also absorbed. Both free and metabolizedisoflavones are excreted by the kidney within 24 hours. Metabolism of isoflavones is also influenced by other components of the diet. A diet rich in carbohydrates results in extensive biotransformation of isoflavones and leads to greater amounts of equol. In the presence of antibiotics that alter intestinal microflora, the metabolism of isoflavones is reduced. ${ }^{52}$

Interest in investigating potential benefits of isoflavones onbone mass came from the data on bone-sparing effects of asynthetic isoflavone, ipriflavone, which has been shown inseveral studies to suppress bone resorption, increase calciumretention in bone, and augment the effects of estrogen onbone. Ipriflavone is structurally similar to soy isoflavones.One of its metabolites, daidzein, is responsible for anestimated $10 \%$ of the actions of ipriflavone. Therefore,ipriflavone in doses between 600 and $1,200 \mathrm{mg} / \mathrm{d}$ seemedan alternative to MHT(menopausal hormone therapy) for postmenopausal women. However,a recent 3-year multicenter study established that it is nobetter than placebo in preventing bone loss and bonefractures inpostmenopausal women, and some womendeveloped lymphocytopenia during ipriflavone treatment. ${ }^{53}$

Genistein increased bone formation, osteoblast number, andosteocalcin level and blocked the increased production ofTNF- $\alpha$, which might be responsible for bone-sparing effectsof genistein. Another possible mechanism of genistein isthought to be through the regulation of B lymphopoiesis. Blymphocytes increase after ovariectomy and secrete TNF- $\alpha$, IL-1, and IL-6, which are involved in bone loss related toestrogendeficiency. ${ }^{54}$

In 2005, the NIH's National Institute of Environmental Health Sciences held a workshop to determine whether phytoestrogens could affect hormonal balance in animals and to address the problem and provide guidance 
concerning the varying estrogen content in commercial diets for laboratory animals. The report determined that study results are confounded by unforeseen levels of isoflavones in animal diets and that the significant variability in estrogenic content between batches resulted in differences in experimental outcomes. The report also concluded that the obvious differences in dietary estrogenic components of soy supplements and tablets could also confound results of clinical studies and questioned the quality of data obtained in human studies. ${ }^{55}$

\section{Tribulus terrestries:}

FSH output and ovulation in infertile women, while the cellular mechanism of this effect remains largely unknown. Rabbits fed Tribulus terrestries extract exhibited differences in the expression of oocyte-derived factors, bone morphogenetic protein 15 , and growth differentiation factor 9 , which are presumed to participate in controlling follicular development and ovulation. ${ }^{56}$

Tribulus terrestriesprevents the developmentof ovarian cysts and polycystic ovarian syndromes in ratsand women. These observations indicate that Tribulus terrestries canpossibly affect female reproductive functions; however, the studiesconducted to date have demonstrated that this plant affectsreproductive functions in healthy females, whether the effects onovarian functions are mediated directly or via upstream hypothalamo-hypophysial and/or peripheral hormonal regulators or whetherpuncturevine can affect ovarian responses to hormonal regulators. ${ }^{57}$

Steroidal saponins may be responsible for the intrinsic hormonal activity of Tribulus terrestries, directly stimulating the endocrine-sensitive female tissues such as the uterus and vagina. It has been proposed that the active components of Tribulus terrestriescan be converted enzymatically into weak androgens similar to DHEA, which could, in turn, be converted intomore powerful androgens such as testosterone in the gonads and peripheral tissues. ${ }^{58}$

Tribulus terrestrieswas more effective in alleviation of menopausal transition symptoms and overall improvement in health-related quality of life. It can be a safer alternative to hormone replacement therapy.

\section{Mucunapruriens:}

On phytochemical analysis, the seeds of Mucunaprurienscontain high concentrations of L-DOPA. Other constituentsinclude gluthathione, lecithin, gallic acid, beta sitosterol, nicotine, dimethyl tryptamine. The leavesalso contain $0.5 \%$ L-DOPA. ${ }^{63}$ The plant is used against a wide range of conditions whichinclude neurological, menstrual disorders, urinary tract problems, fever, ulcers and constipation. It is alsouseful as a hypoglycemic, vermifuge, antihypertensive and carminative agent. ${ }^{64}$

In a study, an increase in the wet weight and dry weight of uteri in standard and the test group of mice proves to be the estrogenic activity of ethanolic extract of Mucunapruriens. It is also supported by the results obtained by others researchers too. Administration of estrogenor progesterone to adult or ovariectomised rats is known to elevate significantly wet weight of uterus, cervix and vagina albeit the estrogen is found to exert more pronounced action. ${ }^{65}$

Mucunapruriens, also known as Velvet Bean, Mucuna pruriens has been used for centuries by Ayurvedic herbalists for overall wellness. Mucunapruriensprovides support for brain function, muscle health and libido. Mucunaprurienshas also been shown to have diuretic effects. It increases tissue resiliency and improves coordination. Mucunapruriens can also increase testosterone levels, which in turn can lead to increased muscle mass and strength. It also supports the nervous and reproductive systems in the body. anti-oxidant activity of Mucunaprurienshas been also demonstrated in vitro by its ability to scavenge DPPH radicals and reactive oxygen species. This is an excellent natural source of L-dopa and 5-hydroxy tryptophan (5-HT). ${ }^{66}$

\section{L- Arginine and Grape Seed Extract:}

The regulatory role of nitric oxide (NO) in vaginal has been studied by the researchers since long time. We used specificinhibitors of enzymes in the NO-cyclic GMP (NO-cGMP) pathway and investigated their effects onvaginal blood flow in the rabbit. NO synthase (NOS) activity was similar in both the proximal anddistal rabbit vagina; whereas, arginase activity was 3.4-fold higher in the distal vagina. Intravenousadministration of the NOS inhibitor L-NAME resulted in a 66\% reduction in genital tissueoxyhaemoglobin and a 53\% reduction in vaginal blood flow. This attenuation occurred despite a20-30\% increase in systemic arterial pressure. ${ }^{67}$

Nitric oxide (NO) is an endogenous anti-atherogenic molecule. Endothelial dysfunction, resulting from depressed NO bioavailability, has been demonstrated in the presence of atherosclerotic risk factors, ${ }^{68-71}$ even in the absence of 
angiographic evidence of atherosclerosis. ${ }^{69,71}$ Moreover, the magnitude of coronary endothelial dysfunction was a potent predictor of major cardiovascular events. ${ }^{72}$

Finally, interventions improving NO bioavailability, such as cholesterol lowering, ${ }^{73}$ are able to favourably affect prognosis. Therefore, correction of endothelial dysfunction is of potential clinical relevance. Ageing, a potent cardiovascular risk factor, is associated with progressive impairment of endothelial function. This has been proven for various indices of endothelial function, such as vasodilatory responses to acetylcholine or methacholine in the epicardial arteries, coronary and ${ }^{71,74,75}$ resistance vessels, as well as the contribution of NO to acetylcholinemediated forearm ${ }^{76}$ and coronary dilationand to basal vascular tone within the forearm ${ }^{77}$ and coronary circulation.

Flow-mediated dilation of the brachial artery is a useful non-invasive index of endothelial function, whichis decreased in the presence of atherosclerotic risk factors, including age even in the subjects without known other risk factors, ${ }^{78}$ as well as in the elderly without clinical evidence of cardiovascular disease.

Local intra-arterial administration of 1-arginine, a substrate for NO synthesis, is known to improve impairedendothelial function within the coronary and forearm vascular beds in healthy old age, but without effect inyounger subjects with normal endothelial function. ${ }^{79}$

NO is synthesized in endothelial cells from the amino acid L-arginine by the enzyme endothelial NO synthase (eNOS). NO rapidly diffuses to vascular smooth muscle cells where it stimulates soluble guanylate cyclase, inducing cGMP-dependent vasodilation. Thus, reduced NO bioavailability following physiological stimulation of arterial endothelial cells manifests as impaired arterial dilation. ${ }^{80}$

Another non-hormonal and effective treatment are pure, uncontaminated grape seed extract. A 2014 study of 96 menopausal women aged 40 to 60 received either placebo, or grape seed extract in low dose (100 mg/day) or high dose (200 mg/day). The study was randomized, double-blind, and lasted eight weeks. In the high dose group, there were significant improvements in physical symptoms, hot flashes, insomnia, anxiety, and depression. In both the low dose and high dose groups, blood pressure decreased and muscle mass increased. ${ }^{81}$

Grape seed extract contains a potent class of polyphenol antioxidants known as proanthocyanidins, which do not bind to estrogen receptors. These antioxidants have been studied for their analgesic, anti-infammatory and heartprotective abilities. One proanthocyanidins-rich pine bark extract was found to alleviate menopausal symptoms. Grape seed may prove even more effective, since the proanthocyanidins extracted from grape seed have a higher molecular weight than those extracted from pine bark. That may be why, unlike pine bark, 200 milligrams daily of grape seed extract led to remarkable improvement in anxiety. ${ }^{81}$

Grape seed is one of the richest sources of proanthocyanidins which are polymers offlavan-3-ols with an average degree of polymerization between 2 and 17. Previously, we showed that grapeseed extract (GSE) has anti-oxidative activity, including the abilityto scavenge free radicals. Besides itsanti-oxidative property, it has been suggested that GSE has anti-inflammatory, anti-diabetic, anti-obesity, anti-carcinogenic, andanti-aging effects. ${ }^{82}$

The role of estrogens in breast cancer (BC) development is widely accepted, leading to the development of selective estrogen receptor modulators and aromatase inhibitors for $\mathrm{BC}$ treatment and prevention. However, because of potential adverse effects, healthy women with high risk of BC are hesitant to take them. Preliminary evidence from animal studies shows that grapes may have an aromatase-inhibiting effect, decreasing estrogen synthesis and increasing androgen precursors. We conducted a randomized, double-blind, dose-finding early-phase trial on the effect of grape seedextract (GSE) on estrogen levels. Postmenopausal women who met study inclusion criteria $(\mathrm{N}=46)$ were randomly assigned to daily GSE at a dose of 200, 400, 600, or $800 \mathrm{mg}$ for 12 weeks. Primary outcome was change in plasma levels of estrogen conjugates from baseline to 12 weeks posttreatment. Thirty-nine participants $(84.8 \%$ ) completed thestudy. GSE in the 4 daily doses did not significantly decrease estrogen or increase androgenprecursors. ${ }^{83}$

That means GSE has the effect on estrogen levels at some point. If taken regularly at set dose, that is effective in menopause than it can have the better effect on the menopausal symptoms. 


\section{Conclusion:-}

The search for natural supplement from medicinal plants is being intensified probably because of its fewer side effects, its ready availability and less cost. All the plants in this review have exhibited significant pharmacological activity. The herbs can be effective aphrodisiacs, moreover, isolation and identification of active constituents from plants may bring a dynamic change in the modern world.A healthy sex life contributes to an improved quality of life and can have profound ramifications on emotional and physical well-being. The compounds discussed here have been shown, singly and in combination, to be effective in supporting recovery from sexual dysfunction.

Aphrodite improves the symptoms of menopause in postmenopausal women, and these studies support the effectiveness of Aphrodite in the clinical management of menopausal symptoms. In addition, the absence of negative side effects, which are commonly seen with prescribed hypnotics, suggests that traditional herbal supplements might be a suitable alternative in the treatment of menopausal symptoms.

\section{References:-}

1. Leiblum SR, Koochaki PE, Rodenberg CA. (2006). Hypoactive sexual desire disorder in postmenopausal women: US results from the Women's International Study of Health and Sexuality (WISHeS). Menopause;13(1):46-56.

2. Laumann EO, Paik A, Rosen R.(1999). Sexual dysfunction in the United States: prevalence and predictors. JAMa;281(6):537-44.

3. Lindau ST, Gavrilova N. (2010) Sex, health, and years of sexually active life gained due to good health: evidence from two US population based cross sectional surveys of ageing. BMJ;340:810.

4. Cain VS, Johannes CB, Avis NE, et al. (2003). Sexual functioning and practices in a multi-ethnic study of midlife women: baseline results from SWAN. J Sex Res;40(3):266-76.

5. Thomas HN, Chang CC, Dillon S, et al. (2014). Sexual activity in midlife women: importance of sex matters. JAMA Intern Med;174(4):631-3.

6. Flynn KE, Lin L, Bruner DW, et al. (2016) Sexual satisfaction and the importance of sexual health to quality of life throughout the life course of U.S. adults. J Sex Med;13(11):1642-50.

7. Shifren JL, Monz BU, Russo PA. (2008). Sexual problems and distress in United States women: prevalence and correlates. Obstet Gynecol;112(5):970-8.

8. Thomas, H. N., \& Neal-perry, G. S. (2018). Female Sexual Function at Midlife and Beyond Sexual function Menopause Perimenopause Sexual dysfunction. 45, 709-722.

9. Bell, T. T. (2019). Is Tribulus Terrestris Effective at Increasing Sexual Desire in Adult Women Suffering from Hypoactive Sexual Desire Disorder?1-9

10. Portman DJ, Gass ML. (2014). Genitourinary syndrome of menopause: new terminologyfor vulvovaginal atrophy from the International Society for the Study of Women'sSexual Health and the North American Menopause Society. J Sex Med;11(12):2865-72.

11. Cuerva MJ, Gonzalez D, Canals M. (2018). The sexual health approach in postmenopause:the five-minutes study. Maturitas;108:31-6.

12. Kroll R, Archer DF, Lin Y. (2018). A randomized, multicenter, double-blind study toevaluate the safety and efficacy of estradiol vaginal cream $0.003 \%$ in postmenopausalwomen with dyspareunia as the most bothersome symptom. Menopause;25(2):133-8.

13. Archer DF, Labrie F, Montesino M. (2017). Comparison of intravaginal $6.5 \mathrm{mg}(0.50 \%)$ prasterone, $0.3 \mathrm{mg}$ conjugated estrogens and 10mg estradiol onsymptoms of vulvovaginal atrophy. J Steroid Biochem Mol Biol;174:1-8.

14. Dennerstein L, Guthrie JR, Hayes RD. (2008). Sexual function, dysfunction, andsexual distress in a prospective, population-based sample of mid-aged, Australian-born women. J Sex Med;5(10):2291-9.

15. Avis NE, Brockwell S, Randolph JF Jr. (2009). Longitudinal changes in sexual functioningas women transition through menopause: results from the Study ofWomen's Health Across the Nation. Menopause;16(3):442-52.

16. Cyranowski JM, Bromberger J, Youk A. (2004). Lifetime depression history andsexual function in women at midlife. Arch Sex Behav;33(6):539-48.

17. Thomas HN, Hamm M, Hess R. (2018). Changes in sexual function among midlifewomen: "I'm older. and I'm wiser". Menopause;25(3):286-92.

18. Hamilton LD, Julian AM. (2014). The relationship between daily hassles and sexualfunction in men and women. J Sex Marital Ther;40(5):379-95. 
19. Sprecher S. (2002). Sexual satisfaction in premarital relationships: associations withsatisfaction, love, commitment, and stability. J Sex Res;39(3):190-6.

20. Byers ES. (2005). Relationship satisfaction and sexual satisfaction: a longitudinal studyof individuals in longterm relationships. J Sex Res;42(2):113-8.

21. Women, C. (2010). Medicinal Plants as Alternative Treatments for Female Sexual Dysfunction: Utopian Vision or Possible Treatment in. J Sex Med; 7:3695-3714.

22. Kelly JP, Kaufman DW, Kelley K, Rosenberg L, Anderson TE, Mitchell AA. (2005). Trends in use of herbal and other natural products. Arch Intern Med; 165:281-6.

23. Fukuda S, Watanabe E, Ono N, Tsubouchi M, Shirakawa T.(2006). Use of complementary and alternative medicine and health problems. Nippon KoshuEiseiZasshi; 53:293-300.

24. Akhtari, E., Raisi, F., Keshavarz, M., Hosseini, H., Sohrabvand, F., \&Bioos, S. (2014). Tribulus terrestris for treatment of sexual dysfunction in women: randomized double-blind placebo - controlled study Tribulus terrestris for treatment of sexual dysfunction in women: randomized double-blind placebo - controlled study.DARU Journal of Pharmaceutical Sciences,22(1):1-6.

25. Palacios, S., Soler, E., Ramírez, M., Lilue, M., Khorsandi, D., \&Losa, F. (2019). Effect of a multi-ingredientbased food supplement on sexual function in women with low sexual desire. BMC Women's Health,19:1-7.

26. Rowland DL, Tai W., Seftel, A. (2004). A Review of Plant-Derived and Herbal Approaches to the Treatment of Sexual Dysfunctions. J Sex Marital Ther. ;29(3):185-205.

27. Do J, Choi S, Choi J, Hyun JS. (2013). Effects and mechanism of action of a Tribulus terrestrisextract on penile erection. Korean J Urol.;54(3):183-188.

28. Patel DK, Kumar R, Prasad SK, Hemalatha S. (2011). Pharmacologically screened aphrodisiac plant-a review of current scientific literature. Asian Pacific J Trop Biomed.;1(1): S131-S138.

29. Gauthaman K, Ganesan AP, Prasad RN. (2003). Sexual effects of puncture vine (Tribulus terrestris) extract (protodioscin): an evaluation using a rat model. J Altern Complement Med.;9(2):257-265.

30. Adimoelja A. (2000). Phytochemicals and the breakthrough of traditional herbs in the management of sexual dysfunctions. Int J Androl.;23(S2):82-84.

31. Nunes, C. P., Geller, M., Oliveira, L., \& Santos, A. (2014). Clinical Assessment of Tribulus terrestrisExtract in the Treatment of Female Sexual Dysfunction. Clinical Medicine Insights: Women's Health.7:45-50.

32. Esfandiari, A. (2016). Effect of Tribulus terrestrisExtract on Ovarian Activity in Immature Wistar Rat: A Histological Evaluation. Journal of Animal and Veterinary Advances.10(7):883-886.

33. Hassan, M., Moghaddam, G., Khalili, M.(2013). The Effect of Oral Feeding of Tribulus terrestris L. on Sex Hormone and Gonadotropin Levels in Addicted Male Rats.IJFS,7(1):57-62.

34. Neychev, V., \&Mitev, V. (2015). Pro-sexual and Androgen Enhancing Effects of Tribulus terrestrisL.: Fact or Fiction. Journal of Ethnopharmacology. 15:1-41.

35. Divya, B. J., Suman, B., Venkataswamy, M., \&Thyagaraju, K. (2017). The Traditional Uses and Pharmacological Activities of Mucuna.Indo American Journal of Pharmaceutical Research.7(1):7516-25.

36. Kavitha C and Thangamani C. (2014). Amazing bean "Mucunapruriens": A comprehensive review Journal of Medicinal Plants Research; 8(2):138-143.

37. State, E. (2019). Effects of Aqueous Leaf Extract of Velvet Bean (MucunaPruriens) on Reproductive Outcome in Adult Female Wistar Rats.J. Appl. Sci. Environ. Manage. 23 (5):995-998.

38. Suresh, S., Prithiviraj, E., \& Prakash, S. (2009). Dose- and time-dependent effects of ethanolic extract of Mucunaprureins Linn. seed on sexual behaviour of normal male rats. Dose- and time-dependent effects of ethanolic extract of Mucunapruriens Linn. seed on sexual behaviour of normal male rats. Journal of Ethnopharmacology, 122:497-501.

39. Shahaji, P. S., \&Parnu, S. A. (2011). Estrogenic activity of Mucunapruriens in Swiss albino mice. International Research Journal of Pharmacy, 2(4):191-193.

40. https://courses.lumenlearning.com/wm-biology2/chapter/hormonal-regulation-of-the reproductivesystem/(Accessed: 9 December 2019)

41. https://embryology.med.unsw.edu.au/embryology/index.php?title=File:HPG_female_axis.jpg(Accessed:9 December 2019)

42. Liu, X., Lin, X., Mi, Y., Li, J., \& Zhang, C. (2018). Grape Seed Proanthocyanidin Extract Prevents Ovarian Aging by Inhibiting Oxidative Stress in the Hens. Hindawi,2018.1-16.

43. Lee, D., \& Kim, J. (2019). Effects of Grape Seed Extract Supplementation on Hemodynamic Response and Vascular Endothelial Function in Postmenopausal Women. Iran J Public Health,48(9): 1735-1737. 
44. Peng, N., Clark, J. T., Prasain, J., Kim, H., White, C. R., Wyss, J. M. (2005). Antihypertensive and cognitive effects of grape polyphenols in estrogen-depleted, female, spontaneously hypertensive rats. Am J PhysiolRegulIntegr Comp Physiol., 289: 771-775.

45. Salmabadi, Z., Sc, M., Kouchesfahani, H. M., Parivar, K. (2017). Effect of Grape Seed Extract on Lipid Profile and Expression of Interleukin-6 in Polycystic Ovarian Syndrome Wistar Rat Model.International Journal of Fertility and Sterility.11(3): 176-183.

46. Ingle JN, Buzdar AU, Schaid DJ, Goetz MP, Batzler A, Robson ME, Northfelt DW, Olson JE, Perez EA, Desta Z, Weintraub RA, Williard CV, Flockhart DA, Weinshilboum RM. (2010). Variation in anastrozole metabolism and pharmacodynamics in women with early breast cancer. Cancer Res.; 70(8):3278-86.

47. Ito, T. Y., Trant, A. S., \& Lake, M. (2011). Journal of Sex \& Marital A Double-Blind Placebo- Controlled Study of ArginMax , a Nutritional Supplement for Enhancement of Female Sexual Function.Journal of Sex \& Marital Therapy, 27: 541-549.

48. Giuliano, F., Rampin, O., \& Allard, J. (2011). Neurophysiology and Pharmacology of Female Genital Sexual Response Neurophysiology and Pharmacology. Journal of Sex \& Marital Therapy, 28(s):101-121.

49. Ito, T. Y., Polan, M. L., \& Whipple, B. (2006). The Enhancement of Female Sexual Function with ArginMax , a Nutritional Supplement, Among Women Differing in Menopausal Status. Journal of Sex \& Marital Therapy, 32:37-41.

50. Hoyle, C. H. V, Robson, T., \& Whitley, K. (1996). Innervation of vasculature and microvasculature of the human vagina by NOS and neuropeptide-containing nerves.J. Anat.,188:633-644.

51. Kim, N. N., Christianson, D. W., \&Traish, A. M. (2004).Role of Arginase in the Male and Female Sexual Arousal Response. J. Nutr.134:2873-2879.

52. Atmaca, A., Kleerekoper, M., Bayraktar, M., \&Kucuk, O. (2008). Soy isoflavones in the management of postmenopausal osteoporosis. Menopause: The Journal of The North American Menopause Society. 15(4): 748-757.

53. Alexandersen P, Toussaint A, Christiansen C. (2001).IpriflavoneMulticenter European Fracture Study. Ipriflavone in the treatment of postmenopausal osteoporosis: a randomized controlled trial. JAMA,285:14821488.

54. Fanti P, Monier-Faugere MC, Geng Z. (1998). The phytoestrogen genistein reduces bone loss in short-term ovariectomized rats. Osteoporos Int.;8: 274-281.

55. J.J. Heindel, F.S. vom Saal. (2008). Meeting report: batch-to-batch variability in estrogenic activity in commercial animal diets-importanceand approaches for laboratory animal research, Environmental Health Perspectives. 116 (3):389-393.

56. Abadjieva D, Kistanova E. (2016). Tribulus terrestris alters the expression of Growth Differentiation Factor 9 and Bone Morphogenetic Protein 15 in rabbit ovaries of mothers and F1 female offspring. PLoS One, 11(2):117.

57. Sirotkin, A. V, Alexa, R., \& Halim, A. (2019). Puncturevine (Tribulus terrestris L.) affects the proliferation, apoptosis, and ghrelin response of ovarian cells. Reproductive Biology, 0-1.

58. Postigo, S., Maria, S., Rosa, R., Silvia, L., Yamada, S., Maximiliano, G., \& Tsutomu, S. (2016). Assessment of the Effects of Tribulus Terrestris on Sexual Function of Menopausal Women Avaliação dos efeitos do Tribulus Terrestrisnasexualidade de mulheres no climatério. Menopause Review/PrzeglądMenopauzalny,16(1):140-146.

59. Freeman, M. and Motsei, M. (1992). Planning Health Care in South Africa - Is There a Role for Traditional Healers? Soc Sci Med., 34 (11):1183-1190.

60. Javed, I., Rahman, Z.U., Khan, M.Z., Muhammad, F., Aslam, B., Iqbal, Z., Sultan, J.I. and Ahmad, I. (2009). Antihyperlipidaemic Efficacy of Trachyspermum Ammi in Albino Rabbits. Acta. Vet. Brno, 78:229-236.

61. Anderson, J.J. and Garner, S.C. (1997). Phytoestrogens and Human Function. Nutr Today, 32 (6):232- 239.

62. Joseph, L.M. (1998). Black Cohosh and Chasteberry: Herbs Valued by Women for Centuries. Clinical Nutritional Insights. Advanced Nutrition Publications, Inc. 6 (15): 1-4.

63. Erowid (2002). MucunaPruriens. Created 2002-APR- 22. International Legume database and Information Service. Genus Mucuna. Version 10.01.

64. Katzenschlager, R; Evans, A; Manson, A (2004). Mucunapruriensin Parkinson disease; a Double Blind Clinical and Pharmacological Study. J. Neurol. Neurosurg. Psychiatry 75:1672-1677.

65. Lednicer D, editor. The physiology of uterus and mammary glands, in contraception, chemical of fertility. The Blackston Division of McGraw Hill Book Company, New York. 1966.

66. Singh, S., Gupta, P. S., \& Gupta, R. (2019). Evaluation of anti-anxiety activity of Mucunapruriens. Journal of Drug Delivery and Therapeutics. 9, 104-107. 
67. Kim, S. W., Jeong, S., Munarriz, R., Kim, N. N., Goldstein, I., \&Traish, A. M. (2003). Role of the nitric oxidecyclic GMP pathway in regulation of vaginal blood flow. 355-361.

68. Celermajer DS, Sorensen KE, Gooch VM. (1992) Non-invasive detection of endothelial dysfunction in children and adults at risk of atherosclerosis. Lancet; 340: 1111-15.

69. Reddy KG, Nair RN, Sheehan HM, Hodgson JM.(1994) Evidence that selective endothelial dysfunction may occur in the absence of angiographic or ultrasound atherosclerosis in patients with risk factors for atherosclerosis. J Am Coll Cardiol; 23: 833-43.

70. Celermajer DS, Sorensen KE, Bull C, Robinson J, Dean. eld JE.(1994) Endothelium-dependent dilation in the systemic arteries of asymptomatic subjects relates to coronary risk factors and their interaction. J Am Coll Cardiol; 24: 1468-74.

71. Quyyumi AA, Darlak N, Andrews NP.(1995). Nitric oxide activity in the human coronary circulation: impact of risk factors for coronary artherosclerosis. J Clin Invest; 95: 1747-55.

72. AI Suwaidi J, Hamasaki S, Higano ST, Nishimura RA, Holmes DR Jr, Lerman A.(2000) Long-term follow-up of patients with mild coronary artery disease and endothelial dysfunction. Circulation; 101: 948-54.

73. Anderson TJ, Meredith IT, Yeung AC, Frei B, Selwyn AP, Ganz P. (1995). The effect of cholesterol-lowering and antioxidant therapy on endothelium-dependent coronary vasomotion. N Engl J Med; 332: 488-93.

74. Egashira K, Inou T, Hirooka Y et al.(1993) Effects of age on endotheliumdependent vasodilation of resistance coronary artery by acetylcholine in humans. Circulation; 88: 77-81.

75. Taddei S, Virdis A, Mattei P et al. (1995). Aging and endothelial function in normotensive subjects and patients with essential hypertension. Circulation; 91: 1981-87.

76. Taddei S, Galetta F, VirdisA .(2000) Physical activity prevents agerelatedimpairment in nitric oxide availability in elderly athletes. Circulation; 101: 2896-901.

77. Lyons D, Roy S, Patel M, Benjamin N, Swift CG. (1997). Impaired nitricoxide-mediated vasodilatation and total body nitric oxide productionin healthy old age. Clin Sci; 93: 519-25.

78. Celermajer Ds, Sorensen KE, Spiegelhalter DJ, Georgakopoulos D, Robinson J, Dean. eld JE. (1994). Aging is associated with endothelial dysfunctionin healthy men years before the age-related decline in women.J Am Coll Cardiol; 24: 471-76.

79. Chauhan A, More RS, Mullins PA, Taylor G, Petch C, Scho. eld PM. (1996)Aging-associated endothelial dysfunction in humans is reversed by Larginine.J AM Coll Cardiol; 28: 1796-804.

80. Verma S, Buchanan MR, Anderson TJ.(2003) Endothelial function testing as a biomarker of vascular disease. Circulation 108: 2054-2059.

81. Terauchi M, Horiguchi N, Kajiyama A, Akiyoshi M, Owa Y, Kato K, Kubota T. (2014). Effects of grape seed proanthocyanidin extract on menopausal symptoms, body composition, and cardiovascular parameters in middle-aged women: a randomized, double-blind, placebo-controlled pilot study. Menopause;21(9):990-6.

82. Jin, G., Asou, Y., Ishiyama, K., Okawa, A., Kanno, T., \&Niwano, Y. (2018). Proanthocyanidin-Rich Grape Seed Extract Modulates Intestinal Microbiota in Ovariectomized Mice.Journal of Food Science. 4-7.

83. Wahner-roedler, D. L., Bauer, B. A., Loehrer, L. L., Cha, S. S., Hoskin, T. L., \& Olson, J. E. (2014). The Effect of Grape Seed Extract on Estrogen Levels of Postmenopausal Women: A Pilot Study. Journal of Dietary Supplements, 11(2), 184-197. 